\title{
Hesselbach's hernia after previous groin surgery
}

\section{Comment to: A rare case of a groin hernia: the Hesselbach's hernia. van den Heuvel et al. (2013) DOI:10.1007/s10029-013-1149-9}

\author{
S. Wood • F. Parkinson • G. L. Williams • \\ B. M. Stephenson
}

Received: 3 October 2013/ Accepted: 21 December 2013/Published online: 7 February 2014

(C) Springer-Verlag France 2014

\section{Dear Editor,}

Primary Hesselbach's herniation [1] is as the authors state very rare [2]. Indeed, varieties of femoral hernia (prevascular and others) seem to be seldom reported and surgeons are unlikely to see more than one in their lifetime.

We should like to share with your readership, a recent case of a 68-year-old man who presented acutely with a tender lump below and lateral to his barely palpable femoral vessels (Fig. 1). He had undergone hip surgery over 10 years earlier through an unusual antero-lateral approach (line on figure). Using a preperitoneal approach, we repaired a $4 \mathrm{~cm}$ lateral defect as a consequence of presumed inguinal disruption. This contained viable omentum, caecum and small bowel and was covered with a piece of flat prosthetic mesh. At 4 year, follow-up the repair remains intact.

As with other unusual groin lumps presenting after previous surgery [3], attending surgeons should be aware that the anatomy may not allow an accurate and sound anatomical closure especially given the proximity of the femoral vessels. An open approach should be considered especially after earlier surgery so as to allow substantial bites of suture to obtain a safe and satisfactory outcome.

This comment refers to the article available at doi:10.1007/s10029-013-1149-9

S. Wood $(\bowtie) \cdot$ F. Parkinson · G. L. Williams ·

B. M. Stephenson

Department of General Surgery, Royal Gwent Hospital,

Cardiff Road, Newport NP20 2UB, UK

e-mail: siwood@doctors.org.uk

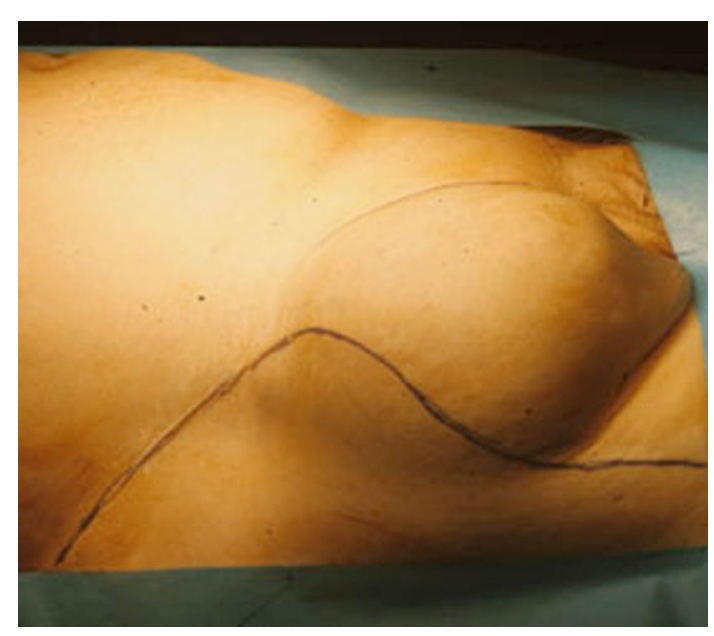

Fig. 1 Right sided Hesselbach's hernia after previous hip surgery

\section{References}

1. Hesselbach FK (1806) Abhandlung uber den Ursprung der Leistenbruche. Anatomisch-chirurgische. Baumgartner, Wurzburg

2. van den Heuvel B, Munoz Brands RM, Beuerle EY, Dwars BJ (2013) A rare case of a groin hernia: the Hesselbach's hernia. Hernia. doi:10.1007/s10029-013-1149-9 (Online access)

3. Williams GL, Riddell A, Coulston J, Frost B, Stephenson BM (2007) Prosthetic repair of prevascular femoral herniation. Hernia 11:513-515 